\title{
The Development of Capacitive Power Transfer for Biomedical Implantable Devices
}

\author{
F.A. Ahmad, S. Saat, N.M. Shaari , M.Z. Mustapa, A.A. Basari
}

\begin{abstract}
Wireless power transfer using electric and magnetic near-fields has been used in many applications widely, and biomedical implants being one of them. The most commonly used method for powering power wirelessly to biomedical implantable device is using inductive coupling between two mutually-coupled coils. In this paper, a consider new method will be proposed in transferring power for biomedical device which is based on capacitive coupling and known as capacitive power transfer $(C P T)$ system. The main reasons of using this method are the low electromagnetic interference (EMI), can reduce power losses and the abilities to transfer power across metal barriers compared to inductive power transfer. To be specific, in this work, we have designed Class E circuit as an inverter to convert the $12 \mathrm{VDC}$ to AC with $1 \mathrm{MHz}$ frequency. The prototype of the capacitive power transfer for implantable application has also been successfully developed with capacitive plate dimensions of $3 \mathrm{cmx} 3 \mathrm{~cm}$ width per length for receiver plate and $4 \mathrm{~cm} \times 4 \mathrm{~cm}$ for transmitter plate, respectively. $5 \mathrm{~mm}$ thickness of beef separation between the plates is used in this paper. The design specification of this work is accordance to stimulator for peripheral nerve implantable device which only needs $100 \mathrm{~mW}$ of power to operate in the CPT system. Overall, the developed CPT system for the biomedical device is able to deliver $76 \mathrm{~m}$ Watt with $41.43 \%$ efficiency. To enhance the efficiency, the impedance matching circuit has been proposed in this work and the prototype is now able to deliver 140m Watt power to the DC load, achieving zero voltage switching (ZVS) waveform and efficiency of $77.5 \%$.
\end{abstract}

Keywords : Capacitive Power Transfer, Impedance Matching, Biomedical Impnatable Devices, Class E Mosfet.

\section{INTRODUCTION}

In the late of 19th century, the discussion about wireless power transmission as a contrasting option to transmission line power dissemination has been explored [1]. The possibility of wireless power transmission has been theorized both by Heinrich Hertz and Nicola Tesla. In 1899, Tesla has revealed the powering of fluorescent lamps 25 miles away

Revised Manuscript Received on October 25, 2019.

* Correspondence Author

F.A. Ahmad, Faculty of Electronics and Computer Engineering, Universiti Teknikal Malaysia Melaka, Melaka, Malaysia. Email: fatinafiqah001@gmail.com

S. Saat*, department of Electronic Eng Faculty of Electronics and Computer Engineering, Universiti Teknikal Malaysia Melaka, Melaka, Malaysia. Email: shakir@utem.edu.my

N. M. Shaari, Faculty of Electronics and Computer Engineering, Universiti Teknikal Malaysia Melaka, Melaka, Malaysia. Email: nurulmuslimahmeorshaari@gmail.com

M. Z. Mustapa, Faculty of Electronics and Computer Engineering, Universiti Teknikal Malaysia Melaka, Melaka, Malaysia. Email: m.zaki5377@gmail.com

A. A. Basari, Department of Electronic Engineering, Faculty of Electronics and Computer Engineering, Universiti Teknikal Malaysia Melaka, Melaka, Malaysia. Email: amat@utem.edu.my from the power source without utilizing wires [1]. It was the first of public WPT showing to power a "typical" load between large capacitive plates [2]. Again, Tesla demonstrated electromagnetic induction through a separation and turned out to be more flexible for wireless power usage. In the era of 1900s, the inductive power transfer (IPT) methods by Tesla evolved and a few far-field radiative procedures were likewise advanced [3].

The transmission of electrical energy without wires is called wireless power transfer (WPT). WPT can be accomplished by creating electric, magnetic or electromagnetic coupling between a device and its counterpart [4]. This innovation can be another option to control electrical gadgets while interconnecting wires are troublesome, unsafe, or are impractical. WPT framework is utilizing the fundamental idea as appeared in Figure 1. The essential side includes DC-to-AC resonant converter that will convert DC control supply to high frequency AC energy. An energy transfer medium will then transferred the AC energy to the auxiliary side of receiver. The auxiliary side is not associated electrically to the essential side. High frequency AC energy is then changed by an AC-to-DC converter to meet the requirements indicated by the load parameters [5].

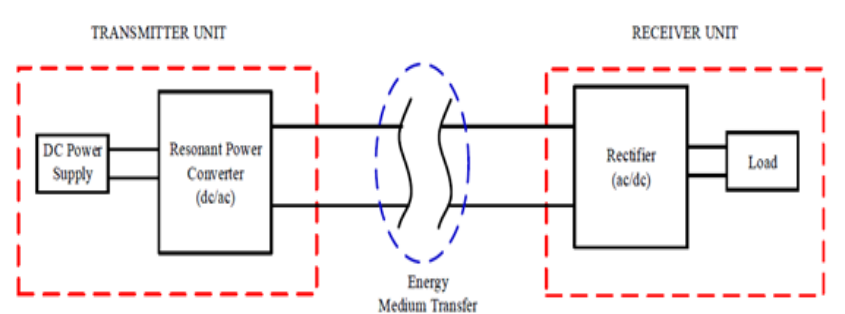

Figure 1: General Diagram of WPT

Wireless power techniques have two categories which are near-field and far-field. As for far-field or radiative techniques, which is also called power beaming, power is transmitted by beams of electromagnetic radiation, corresponding to microwaves or laser beams. As for near field techniques as shown in Error! Reference source not found., power is transferred by magnetic fields using inductive coupling between coils of wire, or by electric fields using capacitive coupling between coupling plates. The power transferred in inductive coupling (electromagnetic induction or inductive power transfer, IPT), is occurring between coils of wire by a magnetic field. The transmitter and receiver coils together will act like a transformer. In capacitive coupling (electrostatic induction, CPT), the conjugate of inductive coupling, energy is transmitted between electrodes such as metal plates by electric fields. The transmitter and receiver plates will act like a capacitor, with

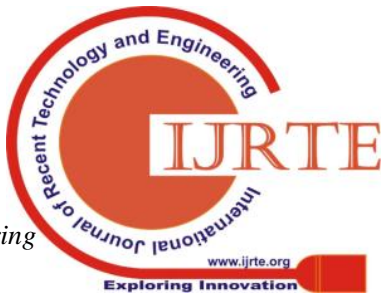




\section{The Development of Capacitive Power Transfer for Biomedical Implantable Devices}

the intervening space as the dielectric

IPT system is the most familiar energy transfer system nowadays where it utilizes coupled of the electromagnetic field coil. This system is very comparable with capacitive idea of energy transfer, however the capacitive idea utilizes capacitance coupling. The accomplishment of this IPT framework has been demonstrated in numerous applications, for example, assembled in electric vehicles, cell phones, and different sorts of the battery charging framework [7][8][9].

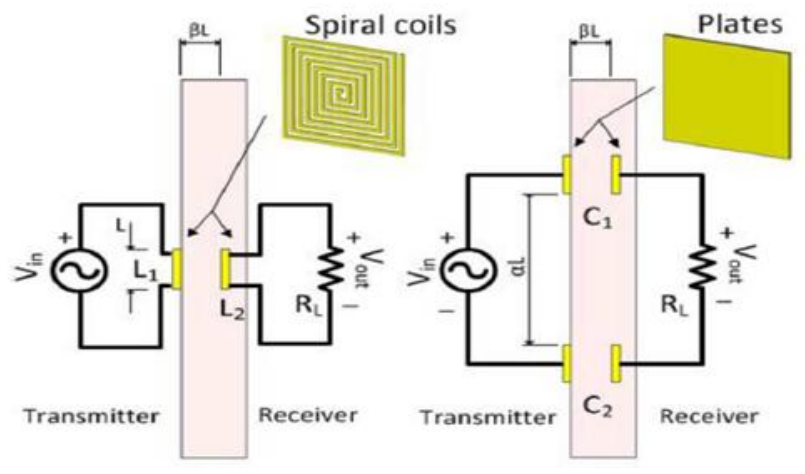

Figure 2: Comparison of IPT and CPT Techniques

However, in contrast of IPT, there are certain advantages of the electric field coupling; the CPT technology can overwhelmed the disadvantage that the magnetic energy could not be transmitted in the metal shielding environment. The CPT technology can transmit through the metal body, reduce energy loss, and also has good anti-interference ability of the magnetic field. Strong anti-interference makes the device able to work in saturated or intense magnetic fields environment, and can reduce energy loss and electromagnetic interference. Therefore, the CPT technology has a number of advantages that IPT technology unparalleled [10].

Transfer power across metal barriers is not possible when it comes to IPT systems as the magnetic field finds the path of least reluctance. Therefore, when the IPT system is placed in an environment, the system has extremely low efficiency. If a metal plate is placed between the primary and secondary coil of the power transfer system, eddy currents are induced in the metal plates and the magnetic field completes the pole to pole completion through the metal plates. Therefore, it will not allow power to be transferred. In the case of CPT systems, the presence of metal barriers does not affect the performance of the wireless system. If a metal plate is introduced between the transmitter and receiver, the metal plate behaves as another plate of a capacitor forming two series capacitors between the transmitter and receiver. The transfer of power remains unaffected and the metal plate introduced also acts as a range extender. Based on this characteristic, the technology is suitable for applications where there are metal objects present between the antenna. Therefore, the systems could be used in charging platforms of mobiles, laptops, electric vehicles etc [11].

Furthermore, the CPT system can be highly efficient due to the absence of eddy currents. In an inductively coupled system, the transmitter and receiver coil are nothing but a loosely coupled transformer. There are always eddy current losses in a transformer. Eddy current losses are inherent in transformers. The coils used can get heated due to the current in them. A CPT system would be a better choice as eddy current losses are absent and the system has low standing power losses. Due to its low standing power losses, the CPT system can be used in biomedical implants [11]. Besides that, we know that the design of magnetics is a complete area by itself. For an IPT system to perform at its best efficiency, the design of the magnetic components is very critical. With introduction in various configuration of coils and cores, the design gets more complicated along the way. However, in case of a CPT system, the design of the system is quite straight forward compared to the IPT system, which makes the CPT system stand out and easily integrable with other circuits.

\section{CAPACITIVE POWER TRANSFER CONCEPT IN BIOMEDICAL DEVICE}

One of the applications of the wireless power transfer system is biomedical implantable devices. Biomedical implants are being used for diagnostic as well as therapeutic purposes. Diagnostic implants are inserted into the patient's body for recording physiological signals such as body temperature, blood pressure, and blood glucose level. Therapeutic implants are used for neuromuscular microstimulation, for instance to control limbs and bowel and bladder muscles, restore vision and hearing, or as miniature drug delivery systems [6]. Biomedical implants such as cochlear, retinal, neural and artificial hearts are mostly powered using transcutaneous transformers which use the principle of inductive coupling. Powering neural implants wirelessly eliminates the need for batteries: this can be achieved inductively and capacitively [4].

By using capacitive power transfer (CPT), compensation and tuning circuitry needed for proper operation can be retained at the transmitting side, hence reduces the complexity of implanted electronics. Moreover, the electric fields in capacitive link are well bounded by the capacitor plates unlike the magnetic fields in an inductive and hence have a better EMI performance and the effects of surrounding metallic elements are minimal [16]. Therefore in this work, the capacitive wireless power technology for biomedical implantable devices will be design as it has more advantages compared to IPT for the purposed of biomedical applications.

Capacitive coupling uses two parallel plate-pairs, separated by tissue. The energy that is fed to the implant is dependent on the electric field in both plate pairs as shown in Figure 3. The skin and tissue act as dielectric material for each capacitor, consisting of two plates: one of these plates is implanted, while the other one is applied to the surface of the skin. The plates are aligned so as to overlap maximally. We will be using small size of receiver plate so it will be more convenient to be implanted inside of the body. The overall development of the CPT system prototype is shown in Figure 3 and the specification of the power operated for the biomedical device application to be designed is according to peripheral nerve stimulator implant which only needs $100 \mathrm{mWatt}$ of power to operate [12]. The Class E circuit will be supply by $12 \mathrm{~V} \mathrm{DC}$ source and then convert it into AC power. The AC energy will then be transmitted to $4 \mathrm{~cm} \times 4 \mathrm{~cm}$ transmitting plate and the powering transfer in AC energy is occurring between $5 \mathrm{~mm}$ beef separation to the $3 \mathrm{~cm} \times 3 \mathrm{~cm}$ receiver plate. In order to supply DC power to the load, the rectifier circuit that receives power from the receiver plate will convert

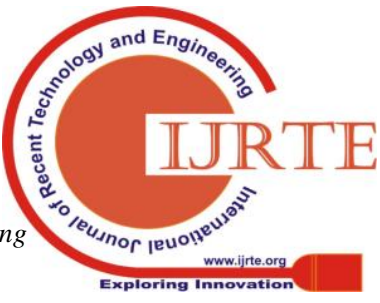


AC to DC energy. The transmitter plate will be larger than receiver plate size since it will be placed outside of the body and to avoid misalignment.

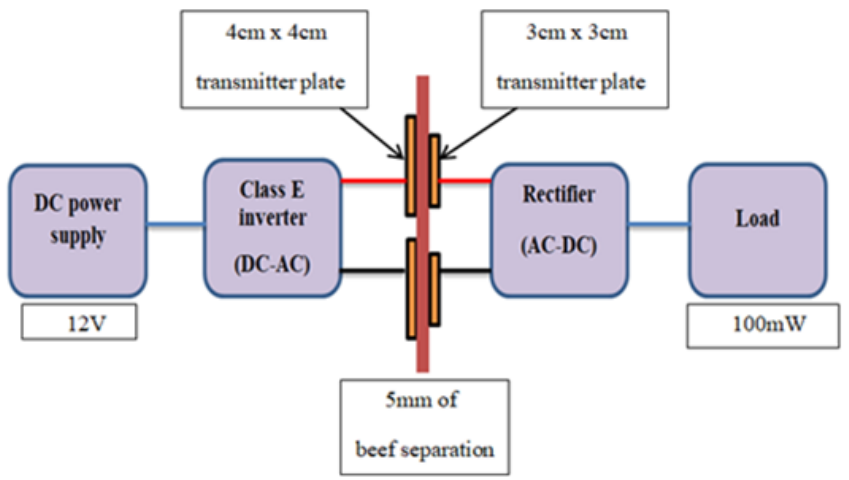

Figure 3: Overall block diagram of the proposed CPT system for biomedical implantable devices.

\section{CLASS E INVERTER CIRCUIT DESIGN}

\section{A. Basic Class E Inverter Circuit Design}

Class $\mathrm{E}$ inverter circuit is part of the design of capacitive power transfer system. The series capacitor, $\mathrm{C}$ component of the Class E inverter circuit as shown in the Figure 4 will later be replaced by the capacitive plate. The class $\mathrm{E}$ circuit is chosen here because it offers an improvised medium of high-frequency, can produce higher efficiency for the output, has advantages in terms of simplicity, and it is a low-noise rectification system [13].

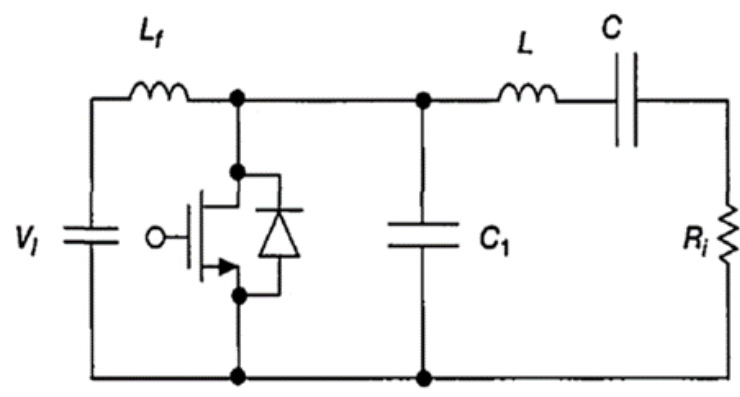

Figure 4: Basic Class E Circuit.

The operating frequency, DC power supply and power output to the load has been described earlier. By using those values, the value of parameters in Class $\mathrm{E}$ inverter can be determined using some related equations. Firstly, the resistance value of load can be calculated by using equation (3.1).

$$
R i=\frac{8}{\pi^{2}+4} \frac{V_{I}^{2}}{P_{R i}}
$$

After that, we can calculate the amplitude of the output voltage by

$$
V_{\text {Rim }}=\frac{4}{\sqrt{\pi^{2}+4}} V_{I}
$$

The maximum voltage across the switch and shunt capacitor is then determined by

$$
V_{S M}=3.562 V_{I}
$$

The DC input current then can be calculated by

$$
I_{I}=\frac{8}{\pi^{2}+4} \frac{V_{I}}{R_{i}}
$$

The maximum switch current is then given by

$$
I_{S M}=\left(\frac{\sqrt{\pi^{2}+4}}{2}+1\right) I_{I}
$$

The amplitude of output current is calculated as

$$
I_{m}=\frac{I_{I} \sqrt{\pi^{2}+4}}{2}
$$

Assuming $Q L=7$, so that the current I through the resonant circuit is sinusoidal. Then, using equation (3.7), (3.8) and (3.9), respectively, the component values of the load network can be determined as follows

$$
\begin{aligned}
& L=\frac{Q_{L} R_{i}}{\omega} \\
& C_{1}=\frac{8}{\pi\left(\pi^{2}+4\right) \omega R_{i}} \\
& C=\frac{1}{\omega R_{i}\left[Q_{L}-\frac{\pi\left(\pi^{2}-4\right)}{16}\right]}
\end{aligned}
$$

Therefore, the efficiency of the output power can be calculated as

$$
\text { Efficiency }(\%)=\frac{\text { PowerOutput }}{\text { PowerInput }} \times 100 \%
$$

\section{B. The Implementation of Impedance Matching in Class E Circuit Design}

In order to improve the maximum power transfer between the source and its load as stated by the author in [14], the implementation of an impedance matching in the Class $\mathrm{E}$ circuit has been proposed in this work. The motivation behind the introduction of impedance matching system is to change over the load resistance or impedance to the impedance required to deliver the desired output power, $P o$ at the specified supply voltage, $V d c$ and the operating frequency, $f$ [15]. The chosen circuit composition of impedance matching network is $\pi 1 \mathrm{~b}$ circuit as shown in the red dotted line of Figure 5.

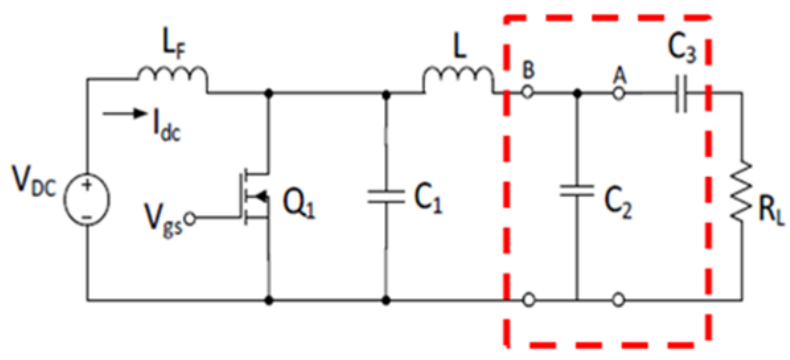

Figure 5: $\pi 1 \mathrm{~b}$ impedance matching circuit.

The different values of parameters used are denoted as $C_{2}$, $C_{3}$ and $R_{L}$ in comparison from the Class E circuit provided in Figure 4. Later, in building the complete CPT system, $C_{3}$ capacitor will be replaced by metal plate for the biomedical implantable application prototype. 


\section{The Development of Capacitive Power Transfer for Biomedical Implantable Devices}

Next, again by using $Q L=7, R_{L}$ is chosen as $300 \mathrm{ohm}$ and $R$ is the value of $R L$ in the previous Class E circuit design, hence, reactance of the capacitor $C_{3}$ can be calculated as

$X_{C 3}=\frac{1}{\omega C_{3}}=R_{L} \sqrt{\frac{R\left[\left(Q_{L}-1.1525\right)^{2}+1\right]}{R_{L}}-1}$

Therefore,

$C_{3}=\frac{1}{\omega X_{C 3}}$

In this case, $R_{L}$ is chosen as $300 \mathrm{ohm}$ since the larger value of $R_{L}$ will give smaller value of $C_{3}$ and thus resulting in smaller size of capacitive plate to be used in biomedical device application.

Furthermore, the reactance of the capacitor $C 2$ is given by

$X_{C 2}=\frac{1}{\omega C_{2}}$

$$
=\frac{R\left[\left(Q_{L}-1.1525\right)^{2}+1\right]}{Q_{L}-1.1525-\sqrt{\frac{R\left[\left(Q_{L}-1.1525\right)^{2}+1\right]}{R_{L}}-1}}
$$

producing

$C_{2}=\frac{1}{\omega X_{C 2}}$

\section{IMPLEMENTATION OF CPT SYSTEM}

\section{A. Simulation Results and Analysis for Class E Inverter Circuit}

Through the calculation based on Class-E design formula as shown in Section 3.1, the Class E circuit parameters can now be obtained and they are shown in Table 1.

Table 1: Class E Components value

\begin{tabular}{|l|c|c|c|}
\hline \multicolumn{1}{|c|}{ Parameters } & Calculation & Simulation & $\begin{array}{c}\text { Percentage } \\
\text { difference } \\
(\%)\end{array}$ \\
\hline Choke inductor, Lf & $115 \mathrm{uH}$ & $200 \mathrm{uH}$ & 73.91 \\
\hline Shunt capacitor, $\mathrm{C} 1$ & $1.76 \mathrm{nF}$ & $1.9 \mathrm{nF}$ & 7.95 \\
\hline Series inductor, $\mathrm{L}$ & $18.5 \mathrm{uH}$ & $19 \mathrm{uH}$ & 2.7 \\
\hline Series capacitor, $\mathrm{C}$ & $1.64 \mathrm{nF}$ & $1.60 \mathrm{nF}$ & 2.43 \\
\hline Load resistor, RL & $16.61 \Omega$ & $17 \Omega$ & 2.35 \\
\hline
\end{tabular}

Values of the components in simulation are different from the calculation one because we need to tune or manipulate the components value to get the best result of ZVS waveform. The simulation work is done using Matlab/Simulink and shown in Figure 6.

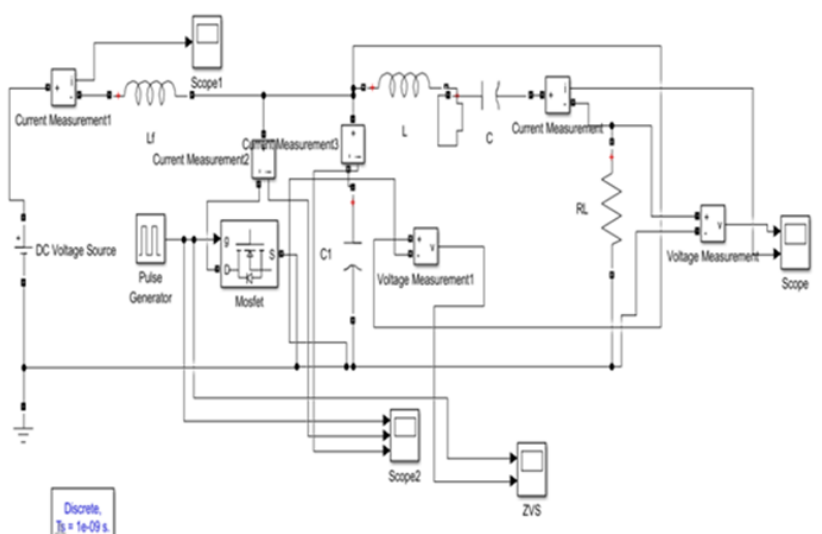

Figure 6: Simulation circuit using Matlab/Simulink

The ZVS simulation result is given in Figure 7(a). From the result, we can see that the VDS Max is $44.12 \mathrm{~V}$ which is recorded in the Class-E system performance in Table 2 as VSM. This value is very close to the calculated one which is 42.74V. Next, based on Figure 7(b), the output maximum voltage reading is $13.84 \mathrm{~V}$ that was recorded as VRim in the Error! Reference source not found. and the value is near to the theoretical one, $13.0 \mathrm{~V}$. The overall performance comparison between theoretical and simulation is then tabulated in Error! Reference source not found.

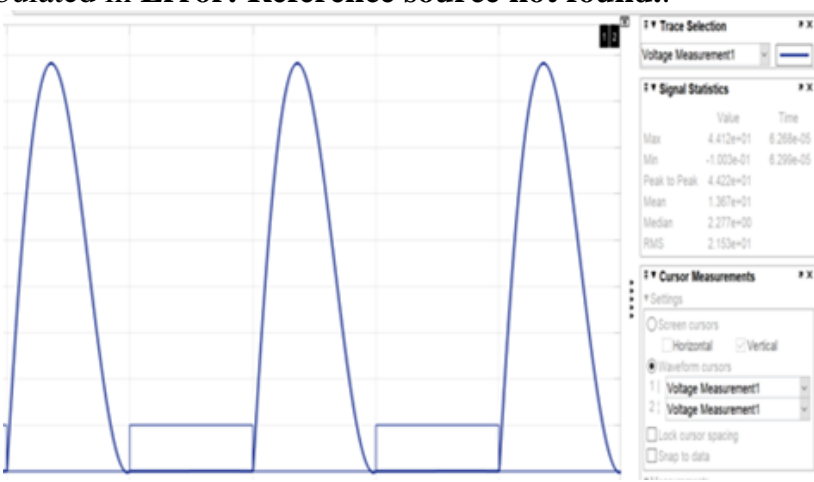

(a)

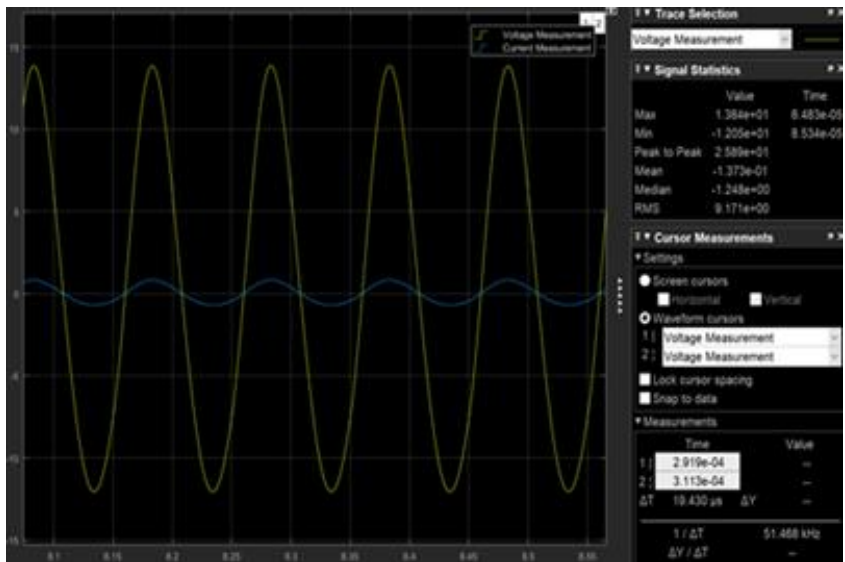

(b)

Figure 7(a): ZVS Performance of the simulation work of Class E circuit

Figure 7(b): Output performance of Class E Circuit 
Table 2: Comparison of system performance in Class E circuit

\begin{tabular}{|l|c|c|c|}
\hline \multicolumn{1}{|c|}{ Parameters } & Calculation & Simulation & $\begin{array}{c}\text { Percentage } \\
\text { difference (\%) }\end{array}$ \\
\hline Input current, Ii & $0.42 \mathrm{~A}$ & $0.41 \mathrm{~A}$ & 2.38 \\
\hline $\begin{array}{l}\text { Gate to source } \\
\text { voltage, VGS }\end{array}$ & $5.00 \mathrm{~V}$ & $5.00 \mathrm{~V}$ & 0 \\
\hline $\begin{array}{l}\text { Maximum } \\
\text { switch current, } \\
\text { ISM }\end{array}$ & $1.19 \mathrm{~A}$ & $0.90 \mathrm{~A}$ & 24.37 \\
\hline $\begin{array}{l}\text { Maximum } \\
\text { switch voltage, } \\
\text { VSM }\end{array}$ & $42.74 \mathrm{~V}$ & $44.12 \mathrm{~V}$ & 3.23 \\
\hline $\begin{array}{l}\text { Output current, } \\
\text { IM }\end{array}$ & $0.78 \mathrm{~A}$ & $0.80 \mathrm{~A}$ & 2.56 \\
\hline $\begin{array}{l}\text { Output voltage, } \\
\text { VRim }\end{array}$ & $13.0 \mathrm{~V}$ & $13.84 \mathrm{~V}$ & 6.46 \\
\hline Power input, Pi & $5.04 \mathrm{~W}$ & $4.92 \mathrm{~W}$ & 2.38 \\
\hline $\begin{array}{l}\text { Power } \\
\text { output,Po }\end{array}$ & $5.00 \mathrm{~W}$ & $4.76 \mathrm{~W}$ & 4.8 \\
\hline Efficiency, \% & $99.20 \%$ & $96.70 \%$ & 2.52 \\
\hline
\end{tabular}

\section{B. Practical Result and Analysis for The Development of CPT System}

In this part, the series capacitor, $C$ of Class-E circuit has been replaced by 2 pairs of copper plate representing forward path of current flow on the left side and reverse path on the right side. Beef is used to replace human tissue in this work and the depth of the beef is $5 \mathrm{~mm}$. Table 3 shows the comparison of the components value used in this work in terms of calculation, simulation and experimental. The values somehow have slightly difference due to the standard value that available in the market and the optimum value for each of the component in order to get the best ZVS waveform.

Table 3: Comparison of Component Value Used

\begin{tabular}{|c|c|c|c|}
\hline Parameters & Calculation & Simulation & Experiment \\
\hline $\begin{array}{c}\text { Choke } \\
\text { inductor, Lf }\end{array}$ & $115 \mathrm{uH}$ & $200 \mathrm{uH}$ & $195 \mathrm{uH}$ \\
\hline $\begin{array}{c}\text { Shunt } \\
\text { capacitor, C1 }\end{array}$ & $1.76 \mathrm{nF}$ & $1.9 \mathrm{nF}$ & $2.1 \mathrm{nF}$ \\
\hline $\begin{array}{c}\text { Series } \\
\text { inductor, L }\end{array}$ & $18.5 \mathrm{uH}$ & $19 \mathrm{uH}$ & $23.1 \mathrm{uH}$ \\
\hline $\begin{array}{c}\text { Series } \\
\text { capacitor, C }\end{array}$ & $1.64 \mathrm{nF}$ & $1.60 \mathrm{nF}$ & $3.3 \mathrm{nF}$ \\
\hline $\begin{array}{c}\text { Load } \\
\text { resistor, RL }\end{array}$ & $16.61 \Omega$ & $17 \Omega$ & $22 \Omega$ \\
\hline
\end{tabular}

\section{(i) Misalignment Analysis}

In this part, some analysis of misalignment for the CPT system will be analyzed and discussed. The experimental setup of this experiment is shown in Figure 8(a).

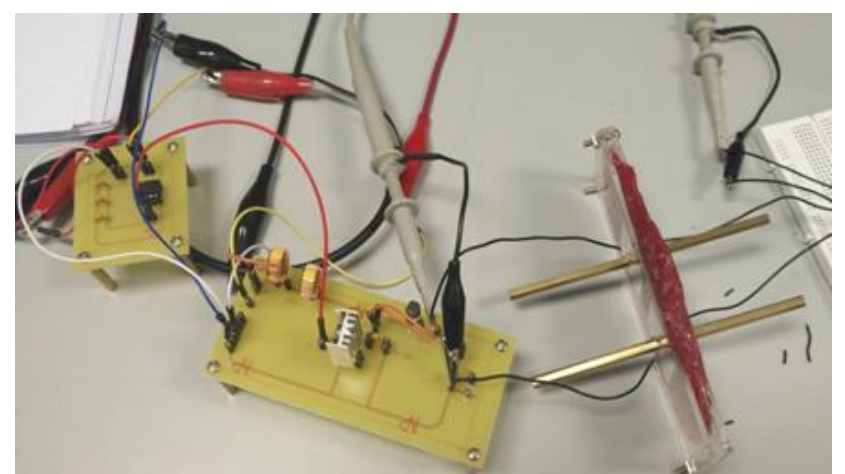

(a)

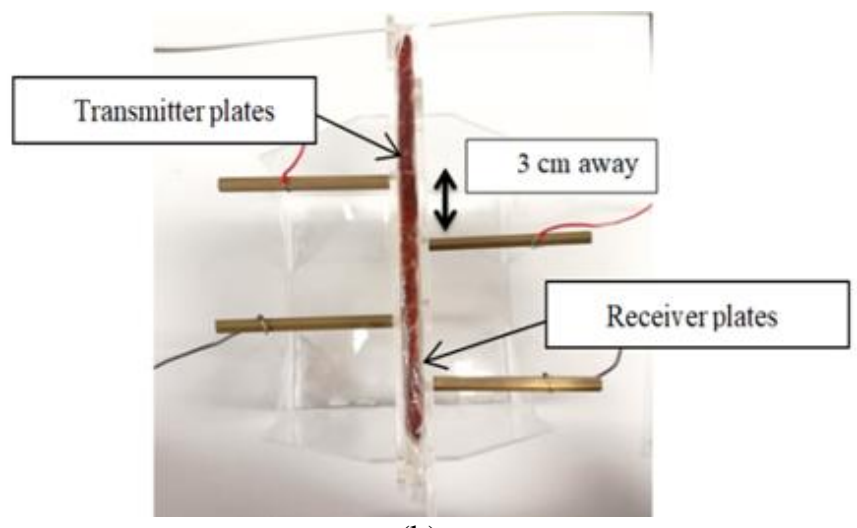

(b)

Figure 8(a): ZVS Performance of the simulation work of Class E circuit

Figure 8(b): Output performance of Class E Circuit

Both of the transmitter and receiver plate with the size of $3 \mathrm{~cm} \times 3 \mathrm{~cm}$ width per length have been used in this experiment. For the analysis of misalignment, the initial condition of the transmitter and receiver plates are in aligned position. After that, the transmitter plates are moved by horizontally away from the receiver plate up to $3 \mathrm{~cm}$ from the original aligned position of the capacitive coupling plates as shown in Figure 8(b). The analysis of misalignment work is shown in Table 4.

Table 4: Misalignment analysis

\begin{tabular}{|c|c|c|c|c|c|c|c|}
\hline $\begin{array}{c}\text { Distan } \\
\mathbf{c e}(\mathbf{c m})\end{array}$ & $\begin{array}{c}\mathbf{V i} \\
(\mathbf{V})\end{array}$ & $\begin{array}{c}\mathbf{I i} \\
(\mathbf{m A})\end{array}$ & $\begin{array}{c}\mathbf{P i} \\
(\mathbf{W})\end{array}$ & $\begin{array}{c}\mathbf{V o} \\
(\mathbf{V})\end{array}$ & $\begin{array}{c}\mathbf{I o} \\
(\mathbf{m A})\end{array}$ & $\begin{array}{c}\text { Po } \\
(\mathbf{W})\end{array}$ & $\begin{array}{c}\text { Efficie } \\
\mathbf{n c y} \\
(\boldsymbol{\%})\end{array}$ \\
\hline 1 & 12 & 362 & 4.34 & 5.23 & 193 & 1.01 & 23.27 \\
\hline 2 & 12 & 297 & 3.56 & 4.34 & 161 & 0.70 & 19.66 \\
\hline 3 & 12 & 197 & 2.36 & 2.01 & 68 & 0.14 & 5.93 \\
\hline
\end{tabular}

The recorded data shows that the input power, Pi and output power, Po are inversely proportional towards the distance of misalignment. This proves that misalignment affects the efficiency of power transfer of the system. Based on Table 4, one can observe that the higher the distance of misalignment, the lower the efficiency of the CPT system. This is actually an important problem to be encountered since the receiver plate will be implanted inside of the body, thus making it hard to be aligned with the transmitter plate when transferring power from outside of the body. Hence, one possible solution to avoid this problem is, the transmitter plates must been made bigger in size compared to the receiver plate. This work chooses $4 \mathrm{~cm} \times 4 \mathrm{~cm}$ width per length.

Next, ZVS performance and output power of the CPT system are studied and the corresponding results are given in Figure 9. From Figure 9(a), the Vds peak to peak value is $35 \mathrm{~V}$ while the $\mathrm{Vgs}$ peak to peak value is $11.3 \mathrm{~V}$ which is high enough to drive the MOSFET. Meanwhile, from Figure 9(b), the obtained output power is $5.7 \mathrm{~V}$. Based on the results, efficiency of the system can be calculated and it gives $41.43 \%$ only. This is not good enough and therefore the impedance matching approach will be proposed next in order to improve the overall performance of such system.

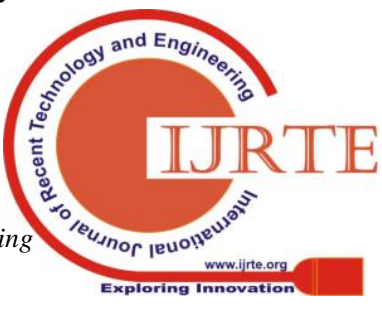


The Development of Capacitive Power Transfer for Biomedical Implantable Devices

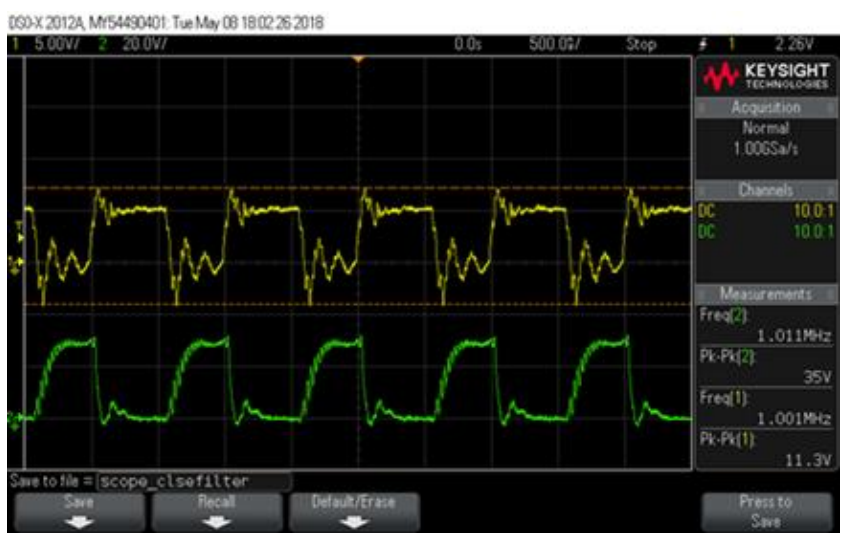

(a)

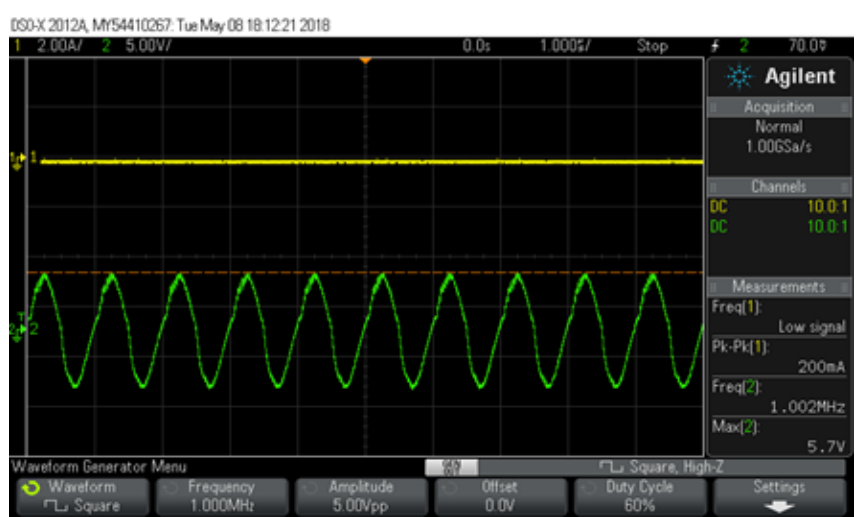

(b)

Figure 9(a): ZVS Performance of the experimental work of Class E circuit

Figure 9(b): Output performance of Class E Circuit

(ii) The Improvement of Class-e Circuit by Impedance Matching Technique

The implementation of impedance matching circuit on the Class E circuit is been approached in order to improve the power efficiency of the CPT system up to $70 \%$. Analysis of the performance of the system and the effect of the higher load resistor value, RL which is $300 \mathrm{ohm}$ on the Class-E circuit will be investigated throughout the impedance matching implementation. Table 5 shows the comparison of components value used in theoretical calculation, simulation and practical work.

Table 5: Comparison on Component Value Used

\begin{tabular}{|c|c|c|c|}
\hline Parameters & Calculation & Simulation & Practical \\
\hline $\mathrm{Lf}$ & $115 \mathrm{uH}$ & $200 \mathrm{uH}$ & $195 \mathrm{uH}$ \\
\hline $\mathrm{C} 1$ & $1.76 \mathrm{nF}$ & $1.9 \mathrm{nF}$ & $2.1 \mathrm{nF}$ \\
\hline $\mathrm{L}$ & $19 \mathrm{uH}$ & $20 \mathrm{uH}$ & $17.75 \mathrm{uH}$ \\
\hline $\mathrm{C} 2$ & $1.3267 \mathrm{nF}$ & $1.25 \mathrm{nF}$ & $1.5 \mathrm{nF}$ \\
\hline $\mathrm{C} 3$ & $0.545 \mathrm{nF}$ & $0.545 \mathrm{nF}$ & $1.2 \mathrm{nF}$ \\
\hline $\mathrm{RL}$ & $300 \Omega$ & $300 \Omega$ & $300 \Omega$ \\
\hline
\end{tabular}

\section{(a) Simulation Results}

In this part, the performance comparison between the circuit with and without impedance matching will be discussed. To note here that the RL used is $300 \mathrm{ohm}$.

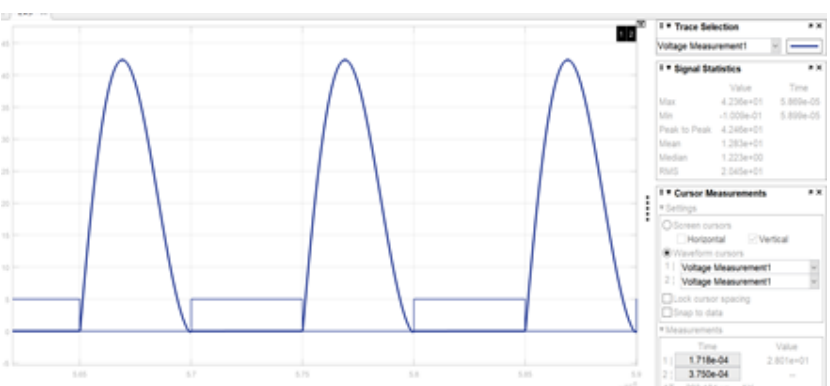

(a)

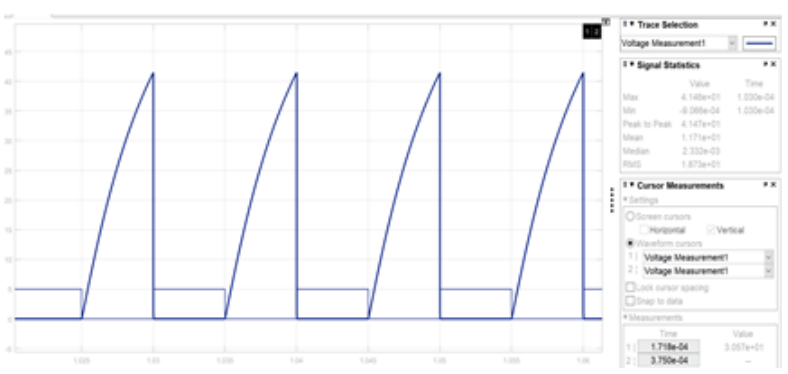

(b)

Figure 10(a): ZVS Performance of the experimental work of Class E circuit

Figure 10(b): Output performance of Class E Circuit

According to Figure 10(a) and Figure 10(b), we can clearly observe that the ZVS performance for the circuit with impedance matching is much better than the one without the matching. Through this we can guarantee that the switching losses of the CPT circuit with impedance matching will be lower than the other one. This will lead to improvement in the overall efficiency later.

In regards to output power, it can be clearly observed that the smooth $A C$ output voltage waveform at $R_{L}$ can be obtained in Figure 11(a) compared to Figure 11(b) that has not implemented impedance matching. The maximum voltage output readings are also having a big difference as Vmax of Figure 11(a) is $50.31 \mathrm{~V}$ and Vmax in Figure 10 (b) is $22.52 \mathrm{~V}$. Next, the comparison of efficiency between the Class E circuit with impedance and without impedance is recorded in Table 6.

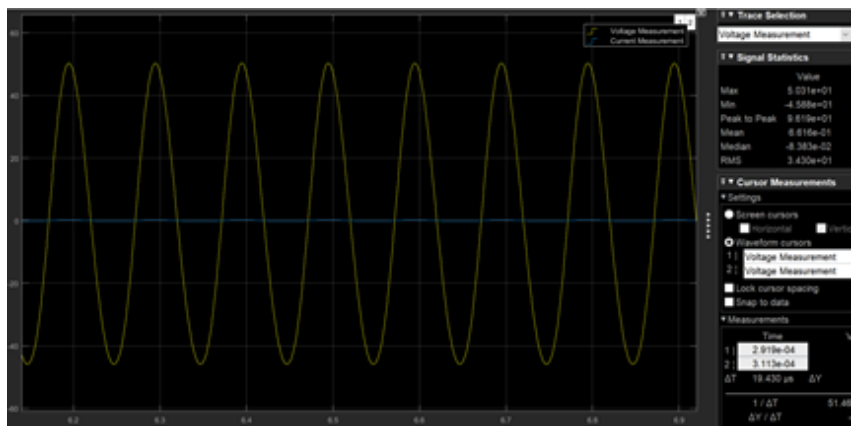

(a) 


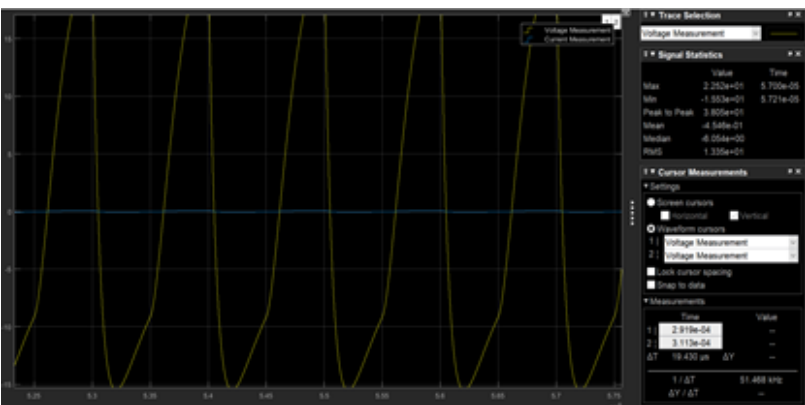

(b)

Figure 11(a): Output voltage with impedance matching Figure 11(b): Output voltage without impedance matching

Table 6: Comparison on Component Value Used

\begin{tabular}{|c|c|c|c|c|c|c|}
\hline Condition & $\begin{array}{c}\text { Vi } \\
(\mathbf{V})\end{array}$ & $\begin{array}{c}\text { Ii } \\
(\mathbf{m A})\end{array}$ & $\begin{array}{c}\text { Pi } \\
\mathbf{W})\end{array}$ & $\begin{array}{c}\text { Vo } \\
(\mathbf{V})\end{array}$ & $\begin{array}{c}\text { Po } \\
(\mathbf{W})\end{array}$ & $\begin{array}{c}\text { Efficien } \\
\mathbf{c y}(\%)\end{array}$ \\
\hline $\begin{array}{c}\text { With } \\
\text { impedance }\end{array}$ & 12 & 350 & 4.2 & 50.31 & 4.08 & 97.1 \\
\hline $\begin{array}{c}\text { Without } \\
\text { impedance }\end{array}$ & 12 & 200 & 2.4 & 22.52 & 0.85 & 35.41 \\
\hline
\end{tabular}

\section{(b) Practical Results}

In this section, the comparison between the Class-E circuit with implementation of impedance matching and without the implementation of impedance matching for $300 \mathrm{ohm} \mathrm{RL}$ will be analyzed experimentally. The overall prototype of the CPT system for biomedical application that has been developed for the practical part analysis is shown in Figure 12

ZVS waveform is able to achieve with impedance matching in Figure 13(a) even though there are some ripples in Vgs. As for Figure 13(b), ZVS waveform could not be achieved in this practical part just like in the simulation part without the impedance matching implementation.

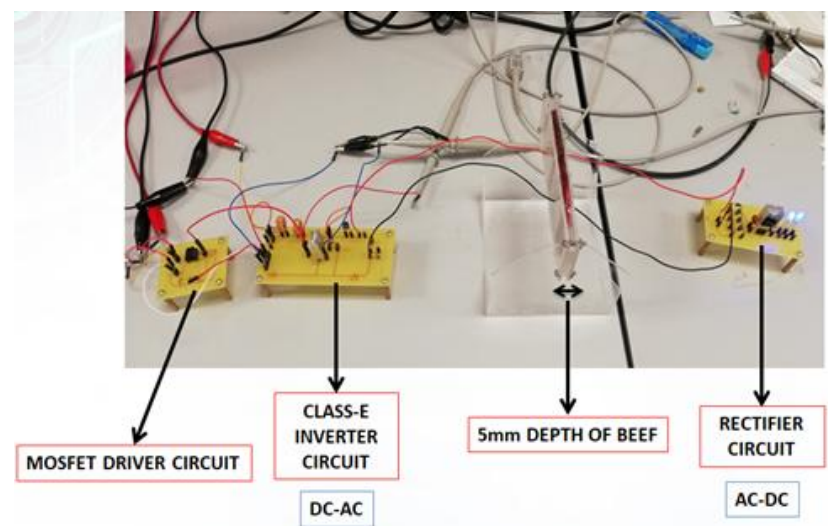

Figure 12: Output voltage with impedance matching

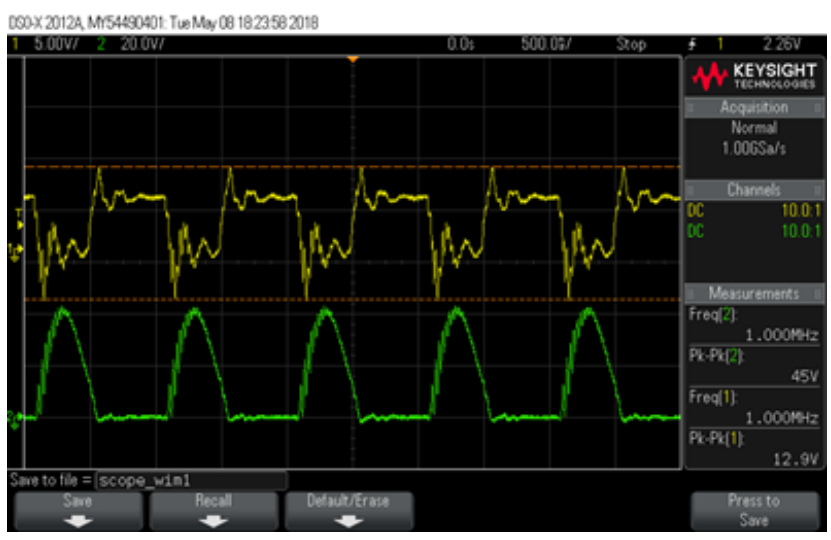

(a)

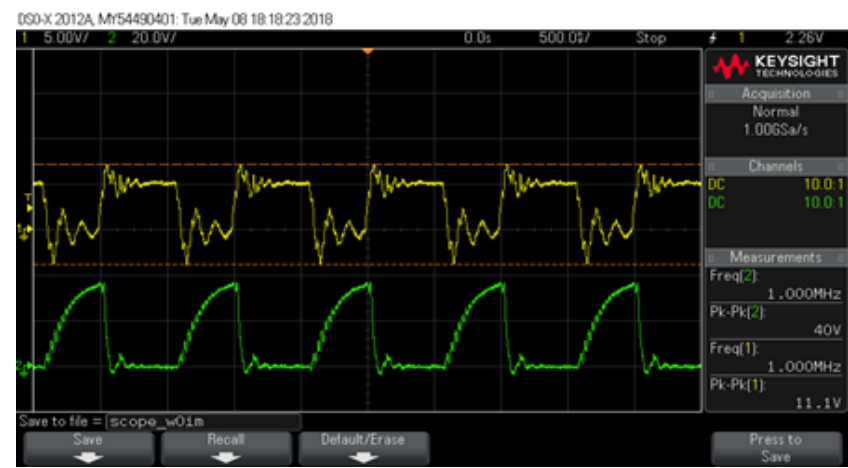

(b)

Figure 13(a): ZVS with impedance matching Figure 13(b): ZVS without impedance matching

The AC output voltage waveform without impedance matching in Figure 14(b) is also not as smooth as the output voltage waveform with impedance matching in Figure 14(a) and Voutput with impedance matching is higher which is $18.6 \mathrm{~V}$ compared to $17.0 \mathrm{~V}$ without impedance matching. The comparison of efficiency is recorded in Table 7.

Table 7: Comparison on Component Value Used

\begin{tabular}{|c|c|c|c|c|c|c|c|}
\hline Condition & $\begin{array}{c}\text { Vi } \\
(\mathbf{V}\end{array}$ & $\begin{array}{c}\mathbf{I i} \\
(\mathbf{m A}\end{array}$ & $\begin{array}{c}\mathbf{P i} \\
\mathbf{( W )}\end{array}$ & $\begin{array}{c}\text { Vo } \\
(\mathbf{V})\end{array}$ & $\begin{array}{c}\mathbf{I o} \\
\mathbf{( m}\end{array}$ & $\begin{array}{c}\text { Po } \\
\mathbf{( W )}\end{array}$ & $\begin{array}{c}\text { Effici } \\
\mathbf{e n c y} \\
(\mathbf{\%})\end{array}$ \\
\hline $\begin{array}{c}\text { With } \\
\text { impedance }\end{array}$ & 12 & 400 & 4.8 & 18.6 & 200 & 3.72 & 77.5 \\
\hline $\begin{array}{c}\text { Without } \\
\text { impedance }\end{array}$ & 12 & 180 & 2.16 & 17.0 & 58 & 0.98 & 45.6 \\
\hline
\end{tabular}

As a conclusion, the impedance matching network implementation on Class-E circuit could improve the efficiency up to $77.5 \%$ of the CPT system even when higher $\mathrm{RL}$ is used as the load. This improvement overall can achieve ZVS waveform nearly to the theoretical and produced higher output voltage. 


\section{The Development of Capacitive Power Transfer for Biomedical Implantable Devices}

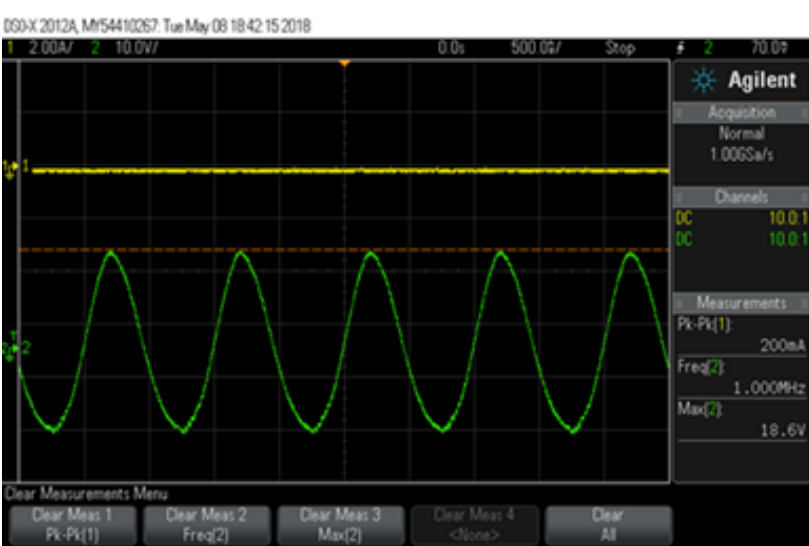

(a)

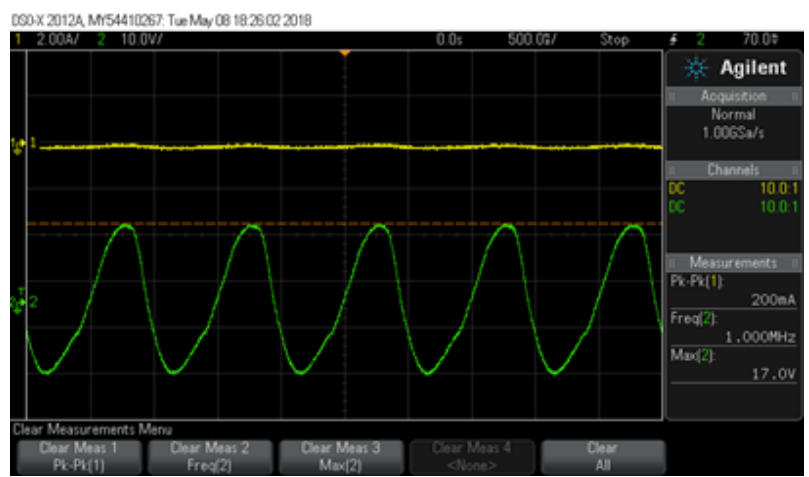

(b)

Figure 14(a): Output voltage with impedance matching Figure 14(b): Output voltage without impedance matching

\section{CONCLUSION}

In conclusion, the overall CPT system that has been designed for the biomedical implantable device is able to deliver $140 \mathrm{~mW}$ att power to the DC load at rectifier circuit by using impedance matching and $76 \mathrm{mWatt}$ power when no impedance matching network available. The specification taken for the biomedical device application in this work is peripheral nerve implantable biomedical device that only needs $100 \mathrm{mWatt}$ power to operate [12]. Hence, the improvement of the Class-E circuit by impedance matching is able to transfer power to the peripheral nerve implantable device wirelessly by the CPT system up to $140 \mathrm{mWatt}$. The main recommendation for this work is to build a CPT system for powering biomedical device wirelessly with smaller receiver capacitor plate. This is due to most of the biomedical devices are small and only need low power in the range of microWatt to miliWatt to operate [17] plus it is easier to implant smaller size of receiver plate inside of the patient's body. Another problem that needs to be considered is the power efficiency of the system. When using smaller capacitor plate size, it is difficult to get a high efficiency so the other type of impedance matching circuit topology can be implemented to investigate the effect of different types of impedance matching network towards the efficiency and performance of the CPT system.

\section{ACKNOWLEDGMENT}

Authors would like to gratitude to Universiti Teknikal Malaysia Melaka and Ministry of Science and Technology
(MOSTI) - 06-01-14-SF0138L00030 for sponsoring this work.

\section{REFERENCES}

1. W.C. Brown, "The History of Wireless Power Transmission," Solar Energy, vol.56, no.1,pp. 3-21, Jan. 1996.

2. J. Dai, " A Survey of Wireless Power Transfer and a Critical Comparison of Inductive and Capacitive Coupling for Small Gap Applications", IEEE Transactions On Power Electronics, Vol. 30 No. 11, November 2015.

3. N. Tesla, "System of transmission of electrical energy," U.S. Patent US 645 576, Mar 20, 1900.

4. R. Jegadeesan, "Wireless Power Transfer To Biomedical Implants," Department Of Electrical And Computer Engineering National University Of Singapore, August 2013.

5. Y. Yusop, S. Saad, S. K. Nguang, H. Husin and Z. Ghani, “Design of Capacitive Power Transfer Using a Class-E Resonant Inverter ,” Journal of Power Electronics, Vol. 16, No. 5, pp. 1678-1688, September 2016.

6. A. I. Al-Kalbani, M. R. Yuce, and J.-M. Redouté, "A Biosafety Comparison Between Capacitive and Inductive Coupling in Biomedical Implants," IEEE Antennas and Wireless Propagation Letters, Vol. 13, 2014.

7. H. H. Wu, A. Gilchrist, K. Sealy, P. Israelsen, and J. Muhs, “A review on inductive charging for electric vehicles," 2011 IEEE Int. Electr. Mach. Drives Conf., pp. 143-147, May 2011.

8. J. Kim and F. Bien, "Electric field coupling technique of wireless power transfer for electric vehicles," IEEE 2013 Tencon - Spring, vol. 1, pp. 267-271, Apr. 2013.

9. F. Musavi, M. Edington, and W. Eberle, "Wireless power transfer: A survey of EV battery charging technologies," 2012 IEEE Energy Convers. Congr. Expo., pp. 1804-1810, Sep. 2012.

10. Y. Zhou, J. Zhang and C. Li, "Comparison of Power Transfer Characteristics between CPT and IPT System and Mutual Inductance Optimization for IPT System", Journal Of Computers, Vol. 7, No. 11, November 2012.

11. D. Rozario, "Design of Contactless Capacitive Power Transfer Systems for Battery Charging Applications", University Of Ontario Institute Of Technology, April, 2016.

12. R. Jegadeesan, S. Nag, K. Agarwal, N. V. Thakor, and Y.-X. Guo, "Enabling Wireless Powering and Telemetry for Peripheral Nerve Implants," IEEE Journal of Biomedical and Health Informatics, vol. 19, no. 3, pp. 958-970, 2015.

13. F. K. A. Rahman and S. Saat, "Design and Simulation of Class-E Power Amplifier for Capacitive Power Transfer System”, MIRJO VOL. 1, ISSUE 1, PP. 14-23, MAY 2016.

14. F.K.A Rahman, S. Saat, Y. Yusop, H. Husin, and Y. Aziz, "Design and Analysis of Capacitive Power Transfer System with and without the Impedance Matching Circuit." International Journal of Power Electronics and Drive Systems (IJPEDS), vol. 8, no. 3, Jan. 2017.

15. Y. Yusop, S. Saat, Z. Ghani, H. Husin, and S. K. Nguang, "Capacitive power transfer with impedance matching network," 2016 IEEE 12th International Colloquium on Signal Processing \& Its Applications (CSPA), 2016.

16. C. Liu, A. P. Hu, "Steady State Analysis of a Capacitively Coupled Contactless Power Transfer System", University of Auckland, 20 Symonds Street Auckland 1010, New Zealand.

17. D. C. Bock, A. C. Marschilok, K. J. Takeuchi, and E. S. Takeuchi, "Batteries used to power implantable biomedical devices," Electrochimica Acta, vol. 84, pp. 155-164, 2012.

\section{AUTHORS PROFILE}

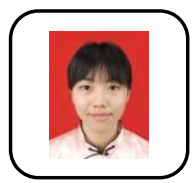

F. A. Ahmad is currently doing Bachelor's Degree in Electronic Engineering majoring in Electronics Industry. She is from Sarawak, Malaysia. 
S. Saat was born in Kedah, Malaysia in 1981. He obtained his bachelor degree in Electrical Engineering from Universiti Teknologi Malaysia and Master in Electrical Engineering from the same university in 2002 and 2006, respectively. Furthermore, he obtained his PhD in Electrical Engineering from The University of Auckland in the field of nonlinear control theory in 2013. He started his carrier as a lecturer at Universiti Teknikal Malaysia Melaka in 2004 and he is now an Associate Professor and Dean at Faculty of Electronic and Computer Engineering of the same university. His research interest is on nonlinear systems control theory and wireless power transfer technologies. He has published one book (published by springer verlag) on polynomial control systems and more than 50 journals and mostly published in the high quality journal such as The Journal of the Franklin Institute, International Journal of Robust and Nonlinear Control, IET Control and etc. More than 30 conference papers have also been published and most of them are in the framework of nonlinear control theory and wireless power transfer technologies. He is also appointed as a reviewer for IEEE Transaction journals, The journal of system science, The Journal of the Franklin Institute, International Journal of Robust and Nonlinear Control, Circuit, systems and signal processing and many more.

N. M. Shaari was born in Terengganu Malaysia. Currently doing Master degree in the field of wireless power transfer technologies

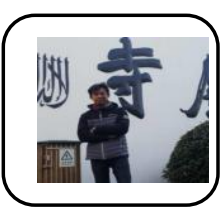

M. Z. Mustapa was born in Melaka Malaysia. Currently doing $\mathrm{PhD}$ degree in the field of wireless power transfer technologies at Universiti Teknikal Malaysia Melaka. He has completed his Bachelor degree and Master degree in the same university in 2014 and 2017 respectively.

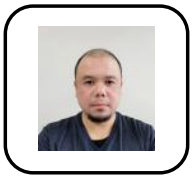

A. A. Basari is a senior lecturer at Faculty of Electronic and Computer Engineering in Universiti Teknikal Malaysia Melaka (UTeM). He obtained his Bachelor, Master and $\mathrm{PhD}$ degree from University of Electro-Communication, Universiti Teknologi Malaysia and Gunma University in 2001, 2006 and 2016 respectively. His research interest is on vehicle suspension system, renewable energy, vibration power generation and recently he is also interested in research of application of artificial intelligence for failure diagnosis. He has published more than 30 journals and proceedings mostly in the indexed journal and proceeding publication. He is also an active reviewer for many reputable journals and proceedings all over the world. 